\title{
Research on the Construction of Urban and Rural Public Distribution System of SY City
}

\author{
Shijun Yuan \\ Hunan Modern Logistics College \\ Changsha, China 410131
}

\author{
Xiangyang Liao* \\ Hunan Modern Logistics College \\ Changsha, China 410131 \\ *Corresponding Author
}

\begin{abstract}
On the basis of analyzing the significance of constructing urban and rural public distribution system, this paper has proposed the construction scheme for the urban and rural public distribution system of special line service in SY City, according to the current situation and demand of urban and rural distribution in SY City.
\end{abstract}

Keywords—urban and rural; distribution system; research

\section{INTRODUCTION}

On December 13, 2017, the Ministry of Commerce, the Ministry of Public Security, the Ministry of Transport, the State Post Bureau, and the Supply and Marketing Cooperatives jointly issued the "Special Action Plan for Urban and Rural Efficient Distribution." This is an important measure for the central ministries and commissions to implement the central government's strategy of revitalizing the countryside and promoting the development of the logistics industry. SY City actively responded to the national policy call and proposed the urban-rural public distribution system construction concept, so that the goals can be achieved, including improving the urban and rural distribution network, optimizing the urban and rural distribution organization, strengthening the application of urban and rural distribution technology standards, promoting the green development of urban and rural distribution, and improving the level of urban and rural distribution management.

\section{SignificAnCE OF THE ProJect CONSTRUCtion}

\section{A. The Project Construction Will Build a Convenient, Safe and Efficient Urban and Rural Logistics Channel}

When traditional agricultural products are transported to cities, they must be loaded and unloaded and transferred in each line, and every time the operation leads to the increase of cost. This project aims at building the public special line distribution, which will realize the direct transfer of agricultural products from the place of origin to the sales area, shortening the time of circulation of agricultural products and guaranteeing their freshness.

\section{B. The Project Construction Will Enable Urban Dealers to Obtain the Best Channel of Stocking Agricultural Products}

The construction of the distribution system for urban and rural public special line makes merchants have the opportunity to better participate in the upstream production of agricultural products, realizing the whole-process quality monitoring, tracing and inquiry of agricultural products from production, supply and sales, in order to guarantee the quality of products and improve the recognition degree of consumers. The distribution under this pattern will further guarantee the freshness of agricultural products through increasing the efficiency of logistics operation. Meanwhile, it will control the retail price of agricultural products and expand the customer group through "high quality and low price" as well as achieve the goal of cost decreasing and benefit increasing.

\section{The Project Construction Will Provide Down-to-earth Distribution Network for the Suppliers of Urban and Rural Commodities}

On the basis of information sharing, the operation pattern of the distribution system for urban and rural public special line proposed in this project is beneficial to merchants to conduct inventory management and launch promotion plans timely. The coexistence of multiple distribution modes enables merchants to select flexibly according to their physical truth, exploits the advantages of the original distribution systems of merchants and meets the various demands of them in distribution.

\section{The Project Construction Will Provide a Convenient Consumption Choice for Urban and Rural Consumers}

The distribution system for urban and rural public special line of two-way flow will guarantee the agricultural products are safe and fresh, with abundant kinds and reasonable price. Urban consumers are able to enjoy the more comfortable and convenient shopping environment of agricultural products. At the same time, rural consumers can also share the consumer goods in life with rural consumers, improving the quality of rural consumers' life. 


\section{ANALYSIS ON THE CURRENT SitUATION AND DEMANDS OF URBAN AND RURAL DISTRIBUTION}

\section{A. Current Situation of Urban and Rural Distribution}

With the continuous progress of the urban and rural integration, logistics distribution between urban and rural areas becomes more and more frequent. The logistics distribution between urban and rural areas includes two aspects: on one hand, farmers transport agricultural and sideline products such as fresh fruits and vegetables, pork, eggs and poultry to cities and guarantee the basic needs of the life of urban residents; on the other hand, agricultural products, industrial products and daily chemical products in cities also provide convenience for the daily life of rural residents. At present, the distribution between urban and rural areas is mainly one-way distribution, and the no-load transportation has led to the increase of transportation cost.

\section{B. Analysis on the Demand of Constructing Urban and Rural} Public Special Line Distribution Service System in SY City

The project construction of distribution system for urban and rural public special line is proposed according to the current situation that most urban and rural distribution is oneway distribution, in order to meet the following demands.

1) The demand of raising the transportation efficiency: The construction of this project will obtain the support of logistics information platform. The distribution system for urban and rural public special line will provide guaranteed two-way supply of goods, form a closed circuit of transportation, so that it will be capable of greatly reducing the time that logistics vehicles look for goods and wait and effectively increasing the utilization ratio and load factors of logistics vehicles and reducing logistics cost.

2) The demand of unblocking the urban and rural commodity circulation: With the soaring development of $\mathrm{O} 2 \mathrm{O}$ like rural e-commerce and fresh fruits and vegetables, the channel for farmers to purchase daily necessities and sell agricultural products has been expanded continuously. The demand for the circulation of products in urban and rural areas is further increased. The construction of the distribution system for urban and rural public special line of this project will meet this demand and further guide the expansion of it.

3) The Demand of Guaranteeing the Security of Rural Consumer Market: The implementation of the policy on the reform of taxation expenses in rural areas and the further improvement of the rural infrastructure construction have tremendously alleviated the economic burden of rural residents and fueled the continuous growth of the demand in rural consumer market. However, the high-cost logistics has given rise to high-price commodities. At present, in some areas, it is still difficult to regulate the channel of stocking commodities, the quality of commodities cannot be guaranteed. Problems such as the rural market consumption is not substantial, unsafe and inconvenient are still common. The construction of the distribution system for urban and rural public special line of this project will guarantee the standard channel of stocking, convenient, efficient and cheap service of logistics distribution and effectively ensure the rural consumer market is safe and convenient.

IV. CONSTRUCTION SCHEME OF THE SERVICE SySTEM OF THE URBAN AND RURAL PUBLIC SPECIAL LinE DisTRIBUTION OF SY CITY

\section{A. General Design Idea}

Taking the demand of the current urban and rural distribution of SY City into full consideration, this project has designed the service system of urban and rural public special line distribution of SY City. The general design idea is as follows:

1) To aim at meeting the urban and rural multi-agent and diversified demand of SY City: First, to meet the demand of farmers for the sales (e-commerce) of agricultural products at the same time consider the demand of purchasing daily necessities; second, to meet the demand of supermarkets for the supply of agricultural products and realize the traceability of the quality of agricultural products; third, to meet the demand of urban customers for the safe, fresh agricultural products with reasonable price; fourth, to meet the demand of electronic commercial enterprises for the expansion of rural consumer market and the execution of cash on delivery; fifth, to meet the demand of express enterprises for "the Last Mile" when going to the countryside; sixth, to meet the demand of rural areas for the distribution of public logistics service of medical apparatus and instruments, drugs, books and letters.

2) To start from constructing the multi-functional distribution terminal that covers the urban and rural areas of SY City with non-blind area: This project will construct modern terminal of distribution service that integrates functions of storage, distribution, distribution processing, commission sale of commodities, commission of tickets and air tickets, Taobao service, express collection (distribution) and the payment of water and electricity and gas fees in counties, administrative towns, villages, groups, cooperation bases, neighborhood committees and communities in SY City through constructing and integrating social resources, and take it as the breakthrough of constructing the service system of urban and rural public special line distribution of SY City.

3) To take the provision of "five fixations" distribution buses as the core competitiveness: The construction of the distribution system for urban and rural public special line adopts the pattern of "distribution bus with five fixations", namely "fixed point (point of loading), fixed line (fixed transportation line), fixed bus number, fixed time (fixed time of arrival and departure) and fixed price (transportation price)", to realize the two-way distribution between urban and rural areas, optimize the distribution path, reduce the intermediate links and guarantee a stronger timeliness. At the same time, it will reduce the loss of agricultural products and increase the efficiency of transportation.

4) To take the real-time sharing of information as the support: The real-time communication and sharing of 
information between participants in the service system of urban and rural public special line distribution of SY City will be realized through constructing the information platform, providing support for the efficient operation of this system.

\section{B. Construction Scheme of the Project}

The distribution system for urban and rural public special line of SY City will construct a sound logistics distribution network of urban-rural integration through "point, line and plane". Meanwhile, a public special line distribution system of urban-rural integration of SY City with perfect functions, reasonable layout and wide coverage will be constructed.

1) To integrate resources to equip distribution vehicles of "five fixations": In the project of the distribution system for urban and rural public special line of SY City (phase I), we will purchase and equip (or integrate resources of social distribution vehicles) 50 sets of special distribution vehicles to meet the distribution demand of urban and rural areas. The urban and rural distribution vehicles will include three types, insulated trucks, refrigerated trucks and ordinary vans to meet the demands of different customers.

Distribution vehicle model 1: 5 sets of distribution vehicles will be allocated, and the weight of each is 10 tons, for the logistics transportation of urban and rural main lines;

Distribution vehicle 2: 30 sets of middle-sized distribution vehicles will be allocated, and the weight of each is 5 tons, for the transportation on branch lines.

Distribution vehicle 3: 50 sets of small-sized distribution vehicles will be allocated, and the weight of each is 1.5 to 3 tons, for the demand of distribution terminals.

The advanced Beidou positioning and navigation system is equipped on all the distribution vehicles. Under the dispatch of TMS transportation management system, the distribution route will be optimized to provide flexible and rapid distribution service for customers.

With the expansion of route and the increase of business volume, the number of vehicle will be increased in the later period. A total of 2 vehicles will be provided every day in general. All the distribution vehicles adopt Beidou navigation and positioning system and the temperature-aware management of Internet of Things to carry out a whole-process monitor of the vehicle position, running speed and vehicle temperature.

2) To construct the service network of urban and rural public distribution: As an integral public service system of logistics, the distribution system for urban and rural public special line of SY City should include 1 first-level public distribution center (municipal public distribution center of SY City to realize the junction of logistics nodes nationwide), more than 87 second-class public distribution centers and nearly 1,000 third-level public distribution terminals. On the basis of full investigation, the second-level and third-level distribution centers cover villages, groups, neighborhood committees and communities of SY City. In the process of practical construction, according to the current distribution center of all areas, the construction of distribution terminals, if condition allowed, it is feasible to reform and improve functions through cooperation and avoid repeated construction, at the same time shorten the construction cycle of the project.

The public distribution terminal is the most basic independent economic entity in the whole system structure at the same time the core unit of the brand-new business model; it is responsible for the packing, coding, scanning and cataloguing of goods sent by urban and rural customers, and of course it can take delivery of goods door-to-door; when goods arrive at the community (village), it is responsible for notifying the owner to take delivery of goods or delivering goods doorto-door; the public distribution terminal can be individual collaborators who are mainly distributed in villages and towns, cooperation, plantation bases, commercial districts, office areas, living areas, wholesale markets and commodity distribution centers; the basic condition include one shop front, one computer, two employees, several deliverymen and simple packaging equipment. A microbus can be allocated if the economic condition is good. At the same time, except for providing the most central distribution service, the public distribution terminal can provide services such as storage, distribution processing, commission sale of commodities, commission of tickets and air tickets, Taobao service, express collection (distribution) and the payment of water and electricity and gas fees according to the actual demand of local customers, and give full play to its functions, for the convenience of the people.

Enormous economic benefit and social benefit will be created when the system network of the urban and rural public special line distribution of SY City is formed.

3) To unify the image to enhance brand influence: All the distribution terminals in the service system of urban and rural public special line distribution of SY City are designed with a unified image, unified logo and are decorated with a unified shop front.

In the service system of urban and rural public special line distribution of SY City, unified vehicle model, vehicle marking, charging and dispatching management are provided for the same level of distribution.

\section{DESIGN OF THE INFORMATION PLATFORM IN THE DiSTRIBUTION SYSTEM FOR URBAN AND RURAL PUBLIC SPECIAL LINE}

\section{A. Target Location of the Platform}

The establishment of information platform will integrate resources of users such as enterprises that supply agricultural materials, merchants, logistics enterprises, express enterprises and farmers and integrate the application systems, realize information sharing, eliminate information isolated island and increase the distribution efficiency of the distribution system for urban and rural public special line and lower the operation cost. The general target of the platform design includes the following aspects: 
(1) To establish a good basic environment for constructing the distribution network of urban and rural public special line

To establish a sound communication infrastructure and equipment and gradually realize the management of the information explosion process of the facilities related to bilateral network through providing infrastructure of data exchange for participants in the distribution system for urban and rural public special line, providing a good hardware and software environment for the rapid development of business.

(2) To build an information platform for the distribution system for urban and rural public special line and realize the whole-process control of the public special line distribution in urban and rural areas, comprehensively integrate the subsystem of platform into a new integrative platform with more powerful functions through system integrated technology, realize the whole-process management of public special line distribution in urban and rural areas relevant to online transaction, product purchasing, product inspection, two-way distribution and settlement.

(3) To realize the information resources sharing between merchants, farmers and logistics enterprises and provide information support for all sides

The information platform will realize a convenient and rapid information exchange of logistics distribution with urban-rural integration through effectively integrating the information of supply and demand of participants in the urban and rural special line distribution system, specifically including supermarkets, distribution centers, and distribution terminals, farmers of all districts and counties and rural cooperation.

\section{B. Design of the Business System of the Platform}

On the basis of the network design of the distribution system for the urban and rural public special line and the analysis on the demand of the information platform, the business system of the information platform for the distribution system of the urban and rural public special line of SY City that includes core business, supplementary service and value added service will be established through analyzing businesses such as electronic commerce and distribution management.

\section{CONCLUSION}

The research on the construction of the urban and rural public distribution system of SY City in this project aims at constructing the logistics distribution network with urban-rural integration that has a sound function, reasonable layout and wide coverage from three dimensions of "point, line and surface". The convenient and fast channel has been constructed for agricultural products to go into town, and fast moving consumer goods to go to the countryside. It is of great significance to improve the living standard and the level of economic development in rural areas.

\section{REFERENCES}

[1] Ye Weiyuan. Research on the Construction of Urban and Rural Public Logistics Distribution System — Taking Lishui City as an Example. Logistics Engineering and Management, 2017(03) (in Chinese)

[2] Ke Ying, Wang Shuying. Research on the Countermeasures of Constructing Chinese Modern Logistics Distribution System [J], Logistics Technology. 2005(08) (in Chinese)

[3] $\mathrm{Xu}$ Maozeng, Yu Guoyin. New Progress of the Research on Urban Distribution [J], China Business and Market, 2014(11) (in Chinese) 